\title{
Demographic Distribution and Long-Term Surgical Outcomes of Intracranial Aneurysms Operated at a Tertiary Health Institute: A Retrospective Study
}

\author{
Tek Referans Hastanesinin Intrakraniyal Anevrizmaların Demografik Dağılımı \\ ve Uzun Dönem Cerrahi Sonuçları: 398 Hastanın Retrospektif \\ Değerlendirilmesi
}

\section{Murad Asiltürk $\odot$}

Department of Neurosurgery, University of Health Sciences, Bakırköy Research and Training Hospital for Neurology Neurosurgery, and Psychiatry, Istanbul, Turkey

Received: 08 February 2020 / Accepted: 24 February 2020 / Publication date: 26 March 2020

Cite as: Asiltürk M. Demographic distribution and long-term surgical outcomes of intracranial aneurysms operated at a tertiary health institute: A retrospective study. Med J Bakirkoy 2020;16(1):15-25.

\begin{abstract}
Objective: To evaluate the demographic distribution and the long-term surgical outcomes of intracranial aneurysms (IAs) at a tertiary health institute.

Method: I retrospectively reviewed the medical records of 398 patients with IAs who underwent surgical intervention at our tertiary health institute within 3 years, between 2011 and 2013. The demographic distribution regarding the patients' cities and their long-term surgical outcomes were evaluated.

Results: Sixty-one (36 females, 25 males) patients were from Istanbul. Majority (14.6\%) of our patients ( $n=120: 71$ females, 49 males) with IAs came from the Marmara region. The locations of IAs in our patients with subarachnoid hemorrhage (SAH) were antrerior communicating artery $(A C O A)(n=78)$, middle cerebral artery (MCA) $(n=74)$, multiple aneurysms (67), internal cerebral artery (ICA) ( $n=24)$, posterior communicating artery (PCOA) $(n=13)$, anterior cerebral artery (ACA) $(n=7)$, superior cerebellar artery (SCA) $(n=6)$, and posterior cerebral artery (PCA) ( $n=5)$, whereas the locations of incidentally diagnosed IAs were MCA (45), ACOA (32), multiple (23), ICA (22), PCOA, ACA, and PCA one each artery. The mortality and morbidity rates were higher in SAH patients $16.7 \%-10.6 \%(15 \%-3 \%$ in patients with incidentally diagnosed IAs). The rate of the patients who returned to their normal daily activities was higher.

Conclusion: A higher rate of postoperative hydrocephalus was observed in patients with multiple aneurysms. There was no relation between sex and morbidity and mortality rates. SAH patients presented with multiple aneurysms had a higher morbidity rate. Advanced age (> 65) and MCA location were associated with a higher mortality rate, while locations of ICA (especially ophthalmic), PCOA, and ACoA were associated with a higher morbidity rate.
\end{abstract}

Keywords: intracranial aneurysm, demographic distribution, subarachnoid hemorrhage, prognosis, incidental aneurysm

öz

Amaç: Intrakraniyal anevrizmaların (IA) demografik dağıımını ve uzun dönem cerrahi sonuçlarını tek referans merkezde değerlendirmektir. Yöntem: 2011-2013 yılları arasında 3 yıllık bir süre boyunca BRSHH hastanesinde intrakraniyal anevrizması olan 398 hastanın tıbbi kayıtları retrospektif olarak incelendi. Hastaların doğduğu şehirlerine ve ait olduğu bölgesine göre demografik dağılım ve uzun dönem cerrahi sonuçları değerlendirdik.

Bulgular: İstanbul'dan 61 hasta (36 kadın, 25 erkek) bizde ameliyat olurken, Marmara Bölgesinden hastalarımızın \%14,6'sını oluşturup (71 kadın, 49 erkek) en fazla hasta kaynağımız olmuştur. En yaygın lokalisyon ACoA (SAK: 78, ins: 32), MCA (SAK: 74, ins: 45), iCA (SAK: 24, Ins: 22), PCoA (SAK: 13, Ins: 1), ACA (SAK: 7, Ins: 1), PCA (SAK: 5, Ins: 1), SCA (SAK: 6, Ins: 0) ve Çoklu anevrizma ise (SAK: 67, incs: 23) hastada saptandı. Mortalite oranları (\% 15: \% 3), morbidite oranları (\% 16.7: \% 10.6) ve (\% 68.3: \% 86.4) hastalar işlerini ve günlük aktivitelerini normale döndürdüler. Komplikasyonları ise postoperatif 58 (SAK: 50, Ins: 8), hidrosefali (SAK: 15, Ins: 3), postoperatif hematom (SAK: 10, Ins: 3), vazospazmaya bağlı kalıcı enfarktüs (SAK: 15, ins: 3) ve jeneralize nöbetler (SAK: 8, Ins: 1)

Sonuç: Postoperatif hidrosefali en çok SAK ile prezente olan çoklu anevrizmalı hastalarda görüldü. Cinsiyet ile ne morbidite ne de mortalite oranları arasında ilişki yoktu. Özellikle çoklu anevrizma tanısı alan SAH hastalarının morbidite oranı yüksekti. ileri yaş (>65) ve MCA yerleşimi yüksek mortalite oranı ile ilişkiliyken, iCA (özellikle paroftalmik), posterior ve anterior kommunikan arterlerinde yerleşim gösteren anevrizmaIı hastalarda yüksek morbidite oranı görüldü.

Anahtar kelimeler: intrakraniyal anevrizma, demografik dağılım, subaraknoid kanama, prognoz, insidental anevrizma 


\section{INTRODUCTION}

Intracranial aneurysms (IAs) are entities that occur as a result of a weakened blood vessel wall, which may be diagnosed incidentally or after an incident of subarachnoid hemorrhage (SAH). As an aneurysm increases in size, so does the risk of rupture. Aneurysms can be the result of a hereditary condition or an acquired disease. IAs are fairly common entities, particularly in hypertensive old population. The patients with unruptured IAs usually complain of nonspecific symptoms such as headache, vertigo or/ and forgetfulness. Rupturing of IAs leads to SAH which has a high propensity to permanent neurological deficits and death ${ }^{(1,2)}$. One literature review published earlier suggested that the incidence of unruptured IAs in healthy individuals can be as high as $6 \%{ }^{(3)}$. Among the patients with IAs, the multiplicity rate ranges between $15 \%$ and $33 \%{ }^{(3,4)}$.

The factors that have an impact on the formation of multiple IAs were investigated in many previously published studies. The multiplicity of IAs are observed to be higher among female, advanced aged, and heavy smoker patients who presented with SAH ${ }^{(5,6)}$. It is suggested that some chronic factors such as chronically increased blood pressure (i.e., hypertension) can influence wall thickness of intracranial arteries. Thus, long-term increase in blood pressure leads to enlargement of the IAs and eventually, they get ruptured. Rupturing of IAs is generally associated with an acute rise in the patients' blood pressure. Initially, the patient can have a single IA or can present with multiple IAs (MIAs). IAs may present as $\mathrm{SAH}$ or may be diagnosed incidentally.

Despite all advancements and refinements of intensive care units, surgical tools, equipments, and micro neurosurgical techniques, aneurysmal SAH has a poor prognosis that remained relatively unaffected (7-10). Through an exhaustive review, we found that SAH has a high mortality rate of up to $40 \%$, while $60 \%$ of the surviving patients with SAH can have serious neurological limitations and need other individuals' support and help ${ }^{(7,11)}$. To manage IAs, good preoperative planning, fine usage of sophisticated surgical equipment, and considerable expertise are necessary. Detailed preoperative planning includes performing digital subtraction angiography (DSA) and other scanning methods such as MRI, MRA, 3D-CT, and CT. The surgical treatment of such entities can be realized only in advanced (tertiary) healthcare centers which were prepared for this challenge ${ }^{(7,8)}$. The current study aimed to investigate the demographic distribution and the long-term surgical outcomes of IAs at a single tertiary healthcare center.

\section{MATERIALS and METHODS}

The current research was retrospective in design and approved under decision 575/2016 fof the board of the medical ethics in our hospital. All patients and/or their next of kin signed written informed consent for surgical interventions and their publication.

I retrospectively reviewed medical records of 398 IA patients who were diagnosed and surgically treated at our hospital, during 3 years from 2011 to 2013. The demographic distribution according to the patients' cities of origin and the long-term surgical outcomes of IAs at a single tertiary healthcare center was discussed.

All statistical data manifested hereafter were given with the ranges within parentheses and expressed as the mean \pm standard deviation values. The one-way analysis of variance (ANOVA) and the SPSS 21.0 statistical package were utilized to assess the differences among groups. Findings were consiered to be statistically significant when the $p$-value was less than 0.05 . All $p$-values were presented with odds ratio (OR). ORs were presented within $95 \%$ confidence interval $(\mathrm{Cl})$.

\section{Surgery}

The patients were placed in supine position with the head holder in the fixation device. A craniotomy is always done on the side of the ruptured or complex, inverse projected aneurysm (in SAH/multiple IA cases). The lateral wall and roof of the orbit were drilled, and thinned using high-speed motors. Accordingly extra space is gained for more exposure of parent vessels to facilitate distal and proximal control of neurovascular structures without further need to retract the neural tissue. The anterior clinoid process can be completely drilled before duratomy step for a safer go-ahead especially in surgeries of 
IAs located on ipsilateral proximal internal carotid arteries (ICAs). To prevent major traumatic pressure and infarcts, we avoid using self-retaining retractors.

To gain further space and get brain further relaxed, before beginning dissection to reach IAs, lamina terminalis was opened except for anteriorly directed anterior communicating artery (ACoA) aneurysms. Opening lamina terminalis is useful for reducing possible SAH-related hydrocephalus in the long term, but the immediate shrinking of the brain, leading to more space without retraction is a major benefit. For incidentally diagnosed IAs that did not present with a $\mathrm{SAH}$, opening lamina terminalis is preferred after clipping if the drainage of the cisternal CSF was satisfactory and cistern was not swollen after SAH. In this way, the surgeon keeps the 3rd ventricular system away from unintended oozing during anatomical dissection.

A retrograde clipping model is adopted in incidentally diagnosed MIAs. That is; neurosurgeon has to start from the deeper IAs (IAs located proximally regarding vessel entry into the cranium, distally according to the surgeon). To emphasize the complete obliterating of IAs from the circulation, I strongly recommend puncturing the dome of the clipped aneurysm with a needle after clipping. Micro-Doppler is utilized to control circulation in vessels distal and proximal to the aneurysm after clipping. As a neurosurgeon, I recommend clipping all reachable IAs in a single session ${ }^{(7)}$.

\section{RESULTS}

A total of 409 micro-clipping surgeries were applied to 398 (216 females and 182 males) patients with IA. IAs were diagnosed after an episode of SAH in 274 patients and IAs were incidentally diagnosed in 124 patients. The most common presenting symptoms are given in Table 1. A total of 308 patients were diagnosed with a single $\mathrm{IA}$ and 90 patients with MIAs. Sixty-five out of 90 multiple IA patients (72.2\%) presented with 2 aneurysms (Table 2 ). The mean age of the whole sample was 50.4 (11-82) years. A total of 61 (36 females, 25 males) patients [15.3\%] were from Istanbul. Most of our patients with IAs ( $n=120$; $30.2 \%$; incl. 71 female, 49 male cases) came from the Marmara region followed by; the Black Sea region (62 women, 57 men) [29.9\%], Eastern Anatolia region (42 women, 38 men) [20.1\%], Central Anatolia (23 women, 23 men) [11.6\%], Southeastern Anatolia (10 women, 8 men) [4.5\%], Mediterranean region (3 women, 2 men) [1.2\%], Aegean region (2 women, 2 men) [1\%] and 6 patients were from abroad [1.5\%] (Fig. 7). The locations of SAH in our patients were as follows: ACOA ( $n=78)$, middle cerebral artery (MCA) $(n=74)$, multiple sites $(n=67)$, ICA $(n=24)$, posterior communicating artery (PCoA) $(n=13)$, anterior cerebral artery (ACA) $(n=7)$, superior cerebellar artery (SCA) $(n=6)$, and posterior cerebral artery (PCA) $(n=5)$, whereas the locations of incidentally diagnosed IAs were as follows: MCA $(n=45), \operatorname{ACo} A(n=32)$, multiple sites $(n=23)$, ICA $(n=22), P C o A, A C A$, and PCA one on each artery. A total of 220 IAs were

Table 1. Baseline clinical and demographic characteristics of the 398 IA patients.

\begin{tabular}{|c|c|c|c|}
\hline & Ruptured Aneurysms & Unruptured Aneurysms & All Pts \\
\hline Age (years) & $51.3 \pm 13.2(11-82)$ & $49.4 \pm 7.4(17-64)$ & $50.4 \pm 11.9(11-82)$ \\
\hline No. Of Patients & 274 pts (68.8\%) & 274 pts (31.2\%) & 398 pts $(100 \%)$ \\
\hline Gender (F/M) & $141 / 133$ & $75 / 49$ & $216 / 182$ \\
\hline Symptoms - Headache & [Severe] $92 \%(n=252)$ & [Chronic] 63.7\% (n=79) & $83.2 \%(331 / 398)$ \\
\hline - Nausea\&Vomiting & $57.7 \%(n=158)$ & $6.5 \%(n=8)$ & $41.7 \%(166 / 398)$ \\
\hline - Impaired consiciousness & $44.2 \%(n=121)$ & 0 & $30.4 \%(121 / 398)$ \\
\hline - Vertigo & $1.8 \%(n=5)$ & $26.6 \%(n=33)$ & $9.5 \%(38 / 398)$ \\
\hline - Generalized seizure & $8.4 \%(n=23)$ & $3.2 \%(n=4)$ & $6.8 \%(27 / 398)$ \\
\hline - Hemiparesis & $7.7 \%(n=21)$ & $2.4 \%(n=3)$ & $6.0 \%(24 / 398)$ \\
\hline - Memory imparment & $1.1 \%(n=3)$ & $7.3 \%(n=9)$ & $3.0 \%(12 / 398)$ \\
\hline - Neck pain & $3.3 \%(n=9)$ & 0 & $2.2 \%(9 / 398)$ \\
\hline - Aphasia / Dysphasia & $2.9 \%(n=8)$ & 0 & $2.0 \%(8 / 398)$ \\
\hline - Behavioral impairment & $2.2 \%(n=6)$ & 0 & $1.5 \%(6 / 398)$ \\
\hline - Fatigue & 0 & $3.2 \%(n=4)$ & $1.0 \%(4 / 398)$ \\
\hline Follow-up period* (months) & 41-77 (Av. 60.1士18.4) & 36-76 (Av. 57.5 \pm 12.1$)$ & 39-77 (Av. 59.3 \pm 21.3 ) \\
\hline Mean length of hospital stay (days) & $9.7 \pm 8.0(4-39)$ & $5.6 \pm 3.5(3-16)$ & $8.4 \pm 7.4(3-39)$ \\
\hline
\end{tabular}

* Follow-up periods were calculated only for patients who are still alive after treatment; pts: patients. 
Table 2. Numbers of aneurysms in multiple cerebral aneurysms patients $(n=90)$.

\begin{tabular}{|c|c|c|c|c|c|c|c|c|}
\hline \multirow[t]{3}{*}{ Numbers of Aneurysms } & \multicolumn{4}{|c|}{ Ruptured Aneurysms } & \multicolumn{4}{|c|}{ Unruptured Aneurysms } \\
\hline & \multicolumn{2}{|c|}{ Females } & \multicolumn{2}{|c|}{ Males } & \multicolumn{2}{|c|}{ Females } & \multicolumn{2}{|c|}{ Males } \\
\hline & $\mathbf{N}$ & $\%$ & $\mathbf{N}$ & $\%$ & $\mathbf{N}$ & $\%$ & $\mathbf{N}$ & $\%$ \\
\hline 2 & 25 & 73.5 & 26 & 78.8 & 8 & 53.3 & 6 & 75.0 \\
\hline 3 & 7 & 20.6 & 6 & 18.2 & 3 & 20.0 & 1 & 12.5 \\
\hline$\geq 4$ & 2 & 5.9 & 1 & 3.0 & 4 & 26.7 & 1 & 12.5 \\
\hline Total & 34 & 100.0 & 33 & 100.0 & 15 & 100.0 & 8 & 100.0 \\
\hline
\end{tabular}

Table 3. Co-morbidities of the all IAs patients.

\begin{tabular}{|c|c|c|c|c|c|c|c|c|}
\hline \multirow[t]{3}{*}{ Co-morbidities } & \multicolumn{4}{|c|}{ Ruptured Aneurysms } & \multicolumn{4}{|c|}{ Unruptured Aneurysms } \\
\hline & \multicolumn{2}{|c|}{ Females } & \multicolumn{2}{|c|}{ Males } & \multicolumn{2}{|c|}{ Females } & \multicolumn{2}{|c|}{ Males } \\
\hline & $\mathbf{N}$ & $\%$ & $\mathbf{N}$ & $\%$ & $\mathbf{N}$ & $\%$ & $\mathbf{N}$ & $\%$ \\
\hline Smoking & 52 & 36.9 & 78 & 58.6 & 26 & 34.7 & 17 & 34.7 \\
\hline Hypertension & 89 & 63.1 & 43 & 32.3 & 45 & 60.0 & 23 & 46.9 \\
\hline Coronary Artery Diseases & 31 & 22.0 & 4 & 3.0 & 2 & 2.7 & 14 & 28.6 \\
\hline Diabetes Mellitus & 18 & 12.8 & 6 & 4.5 & 4 & 5.3 & 18 & 36.7 \\
\hline COPD* & 11 & 7.8 & 8 & 6.0 & 3 & 4.0 & 6 & 12.2 \\
\hline Thyroid Dysfunction & 10 & 7.1 & 2 & 1.5 & 16 & 21.3 & 9 & 18.4 \\
\hline CVA** & 7 & 5.0 & 3 & 2.3 & 5 & 6.7 & 4 & 8.2 \\
\hline
\end{tabular}

* COPD: Chronic obstructive pulmonary diseases; ** CVA: Cerebrovascular accident.

detected as MIAs in 90 patients ( 67 with SAH and 23 incidentally diagnosed cases). The co-morbidities of all patients are given in Table 3. The respective mortality $15 \%$ vs $3 \%)$ [P=0.0002, OR 5.28 (1.85-15.09)], and morbidity rates (16.7\%:vs \%10.6) [P=0.027, OR $1.97(1.0-3.8)]$ were as indicated and the greater proportion of incidentally diagnosed patients with single IAs returned to their normal daily activities (GOS $\geq 4$ ) (86.4\% vs $68.3 \%$ ). The complications such as postoperative infections, hydrocephalus, hematoma, vasospasm and generalized seizures were higher in SAH patients with rates of $(50: 8)[\mathrm{P}=0.001, \mathrm{OR}$ 2.83 (1.48-7.06)], (17:3) [P=0.049, OR 3.07 (0.8810.7)], (10:3) [P>0.05], (15:3) [P=0.086, OR 2.68 (0.76-9.46)], and (8:1) $[P>0.05]$, respectively. Nine out of 17 patients with hydrocephalus had MIAs $[P=0.005$, OR $0.24(0.09-0.64)]$. Even though hydrocephalus was a complication seen after surgery of IA patients with SAH $(n=17)$ and unruptured aneurysm $(n=3)$ patients, this complication was associated with aneurysmal SAH patients especially with MIAs $(P=0.049)$. We found out that infection rates increased coherent to Fisher grade rather than the HuntHess scale (Fisher grade I and II vs Fisher grade III and IV; $\mathrm{P}=0.032$ ).
Postoperative infections were observed in 58 of our patients where 50 patients had presented with SAH initially ( $P=0.001, O R 2.83$ ). In the same period of our study 1361 patients were admitted to ICU for different causes. In the remaining 963 patients, the most common infections were pneumonia, BSI, meningitis, and UTI, respectively. This order was not the same in our aneurysm patients (in decreassing order of frequency: blood site infection (BSI), pneumonia, meningitis, surgical site infection (SSI) and urinary tract infection (UTI), respectively). In patients with $\mathrm{SAH}$, multiple aneurysms and ruptured ACoA aneurysms had high infection rates $(\mathrm{P}<0.05)$ compared to other IAs. Advanced age and female gender (except for pneumonia and UTI), multiple aneurysms (except for meningitis), SAH presentation, increased hospitalization period, delayed surgical intervention and poor neurological status increase risks of the nosocomial infections.

In the SAH group ( $n=274)$, poor neurological grade at presentation, the presence of hematoma, and the impairment of consciousness (high Hunt-Hess grade [IV/V]) are associated with high morbidity and mortality rates; $[(P<0.001, O R$ 0.02); $(P<0.001, O R$ 0.07)], 
[( $P<0.001$, OR 0.22); $(P=0.001$, OR 0.32)], and [( $P=0.003$, OR 0.35) and $(P<0.001, O R 0.07)]$, respectively.

There was no relationship between gender of the patients and the morbidity ( 37 women, 23 men) and the mortality (26 women, 18 men) rates, $(P=0.3, O R 0.8)$ and $(P=0.11, O R 0.67)$, respectively. Advanced age ( $>65$ years) [16 of 59 of these patients died] $(P<0.001, O R 0.24)$ and MCA location [23 of 109 patients with MCA aneurysms died] $(P<0.001$, OR 0.31) were associated with higher mortality rate while ICA location (especially location on paraophthalmic segment) [14 of 46 patients with ICA aneurysms had $\mathrm{GOS}<3$ ] $(\mathrm{P}=0.004, \mathrm{OR} 0.34)$, posterior communicating segment location [5 out of 14 patients ICA aneurysms with $\mathrm{GOS}<3$ ] $(\mathrm{P}=0.044$, OR $0.3)$ and anterior communicating artery location [28 of 82 patients had ICA aneurysms with GOS<3] $(P=0.0005, O R$ 0.37) were associated with higher morbidity rates.

Sixty-one (67.8\%) patients with multiple IAs (GOS $\geq 4$ ), and 233 out of 308 patients with single IA had good outcomes. Seventeen multiple and 44 single IA patients had poor outcomes (GOS $\leq 3$ ) and 12 patients with multiple and 33 patients with single IAs died. The mortality and the morbidity rates were $(P=0.13, O R$ $0.66)$ and $(P=0.27, O R 0.75)$, respectively.

Seven ( 3 men and 4 women) SAH patients with a mean age of $59.4 \pm 5.4$ (51-65) years presented with recurrent SAH. SAH in all seven patients originated from other IAs that were not found in DSA performed at first bleeding episode. The interval between the first and second SAHs ranged between 23 and 122 (average on 70) months. All seven patients were heavy smokers (more than 40 cigarettes a day) with a known hypertensive disease. Five of them presented with MIAs.

\section{Exemplary Cases}

Case 1: A 61-year-old woman brought to our Emergency Department after complaining from a severe headache followed by nausea and vomiting. The neurological examination of this hypertensive

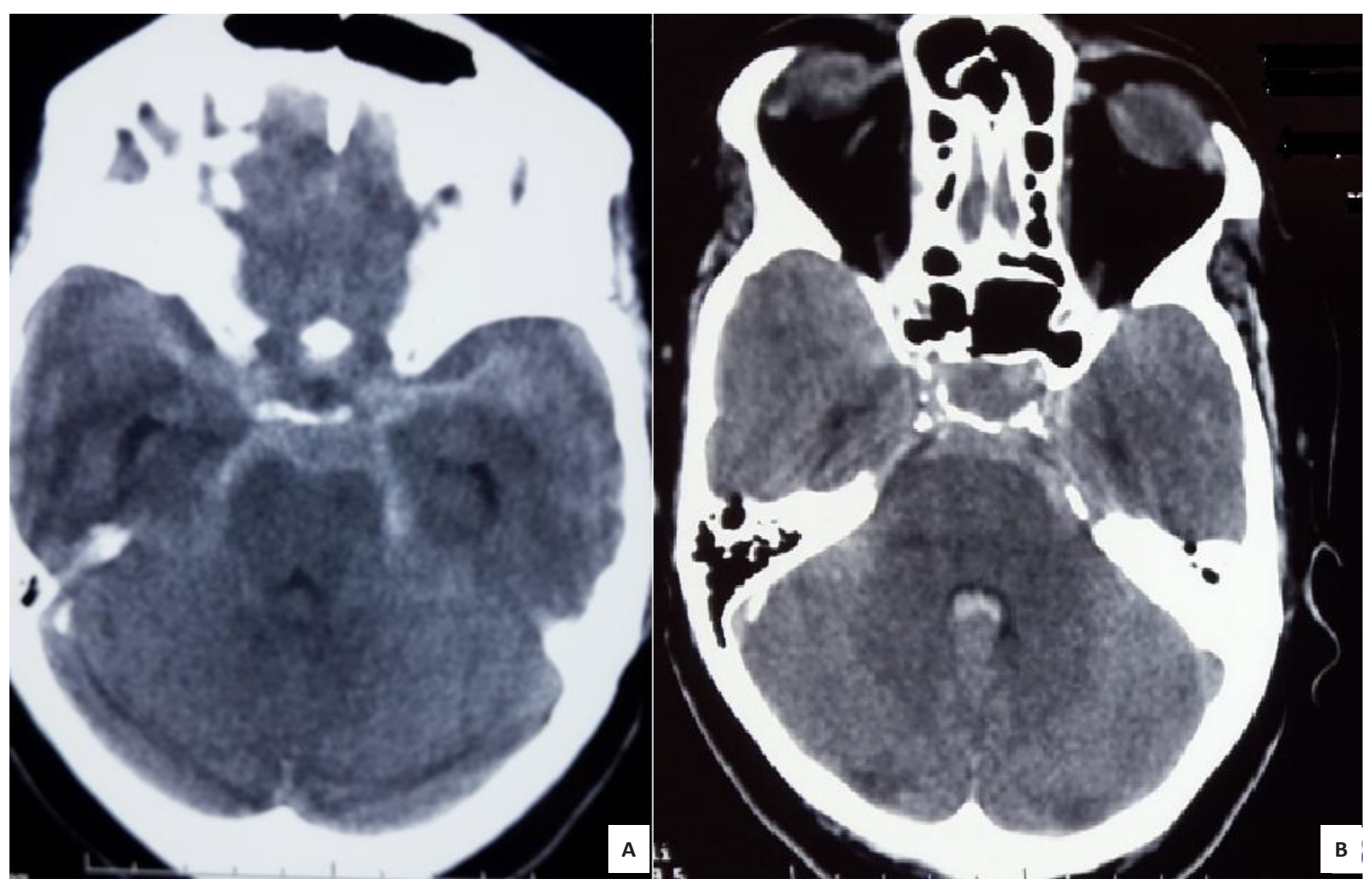

Figure 1. Preoperative cranial computerized tomography (CT) revealed subarachnoid hemorrhage (SAH) that was evaluated as grade 4 in Fisher scale and mild hydrocephalus; [A]: Perimesencephalic SAH and mild hydrocephalus are apparent in temporal horns of lateral ventricle; [B]: Fisher grade IV Intraventricular subatrachboid hemorrhage in the fourth ventricle. 


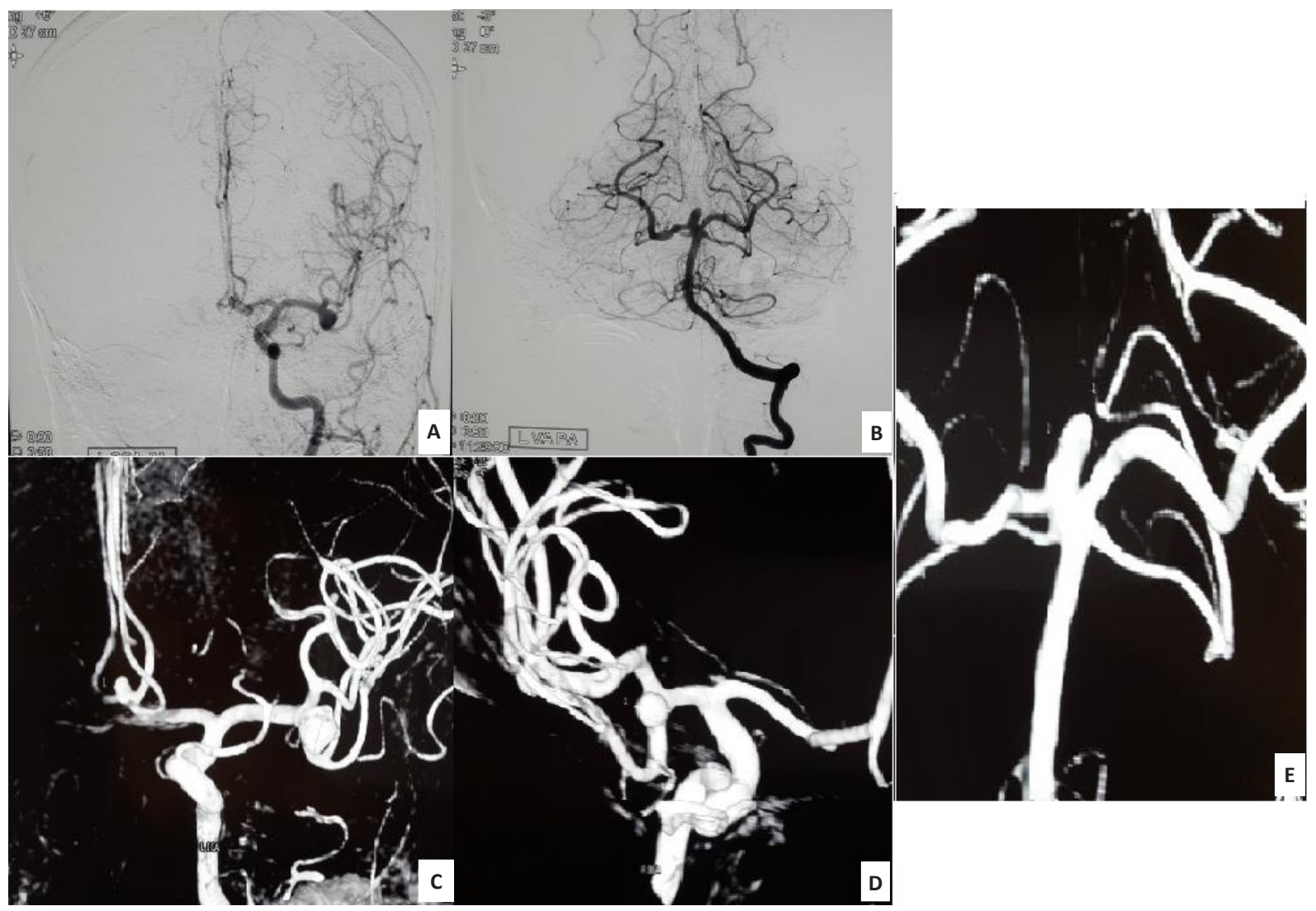

Figure 2. Preoperative DSA demonstrating a case of the multiple aneurysms of bilateral middle cerebral, anterior communicating and basilar arteries; [A]: Preoperative DSA shows left MCA aneurysm; [B]: Preoperative DSA shows basilar artery aneurysm; [C]: Preoperative three-dimensional DSA shows both left MCA and ACoA aneurysms; [D]: Preoperative three-dimensional DSA shows both right MCA and ACoA aneurysms; [E]: Preoperative three-dimensional DSA shows basilar artery aneurysm.

patient was not remarkable Except for the nuchal rigidity (++), she had no neurological deficits (HuntHess grade II). Urgent brain CT demonstrated a SAH accompanied by mild hydrocephalus (Figure 1). Right femoral intraarterial DSA demonstrated MIAs of four separate IAs (Figure 2).

All IAs were successfully clipped through a left lateral supraorbital craniotomy (Figure 3). The patient fully recovered without any neurological deficit and she was discharged on the 7th postoperative day. No complications were recorded.

Case 2: A 38-year-old woman was brought to our outpatient clinics with a headache of 2 years' duration. The patient said that she became tired easily even with a moderate effort. Her neurological examination and vital signs were within normal ranges.

MIAs were detected on bilateral MCA bifurcations on brain MRI and DSA (Figure 4, 5). Both bilateral MCA IAs were successfully clipped through a right lateral supraorbital craniotomy (Figure 6). The patient fully recovered without any neurological deficit and she was discharged on the 4th postoperative day. No complications were recorded.

\section{DISCUSSION}

The advancement of all intensive care units, neurosurgical fields, and equipment types has not proportionately improved the prognosis of $\mathrm{SAH}$, because morbidity and mortality rates still being at an unacceptably high levels ${ }^{(8,9)}$. Many previously published articles reported that patients with MIAs that presented with SAH had less favorable outcomes compared to cases with single aneurysms ${ }^{(5,6)}$. Even though we did not face additional surgical difficulties, our multiple IA cases were associated with a higher rate of postoperative hydrocephalus complications. 
Even though our tertiary hospital is in the European side of Istanbul, $50 \%(n=199)$ of all our patients were born in the Black Sea and Eastern Anatolia regions, the regions close to the Chernobyl area. We interpreted this by one of three possibilities; 1) Environmental factors: greater number of our patients were from the regions close to the Chernobyl nuclear plant accident happened in 1986, 2) Habitual factors such as the patients' feeding pattern, or 3 ) The genetic nature of the disease since consanguineous marriage is common in these areas. Presently, limited evidence exists for the risk for vascular disorders such as IAs associated with radiation exposure emitted from a nuclear plant accident 12).

In our study, we found that surgically treated unruptured aneurysms may reduce the high complication rate which was observed in SAH patients. Therefore, we preferred to operate most of the patients who were diagnosed incidentally. Unruptured IAs are serious entities that have to be treated immediately or observed regarding their size, irregularity of their shape, and the frailty index of the patients ${ }^{(8)}$. The

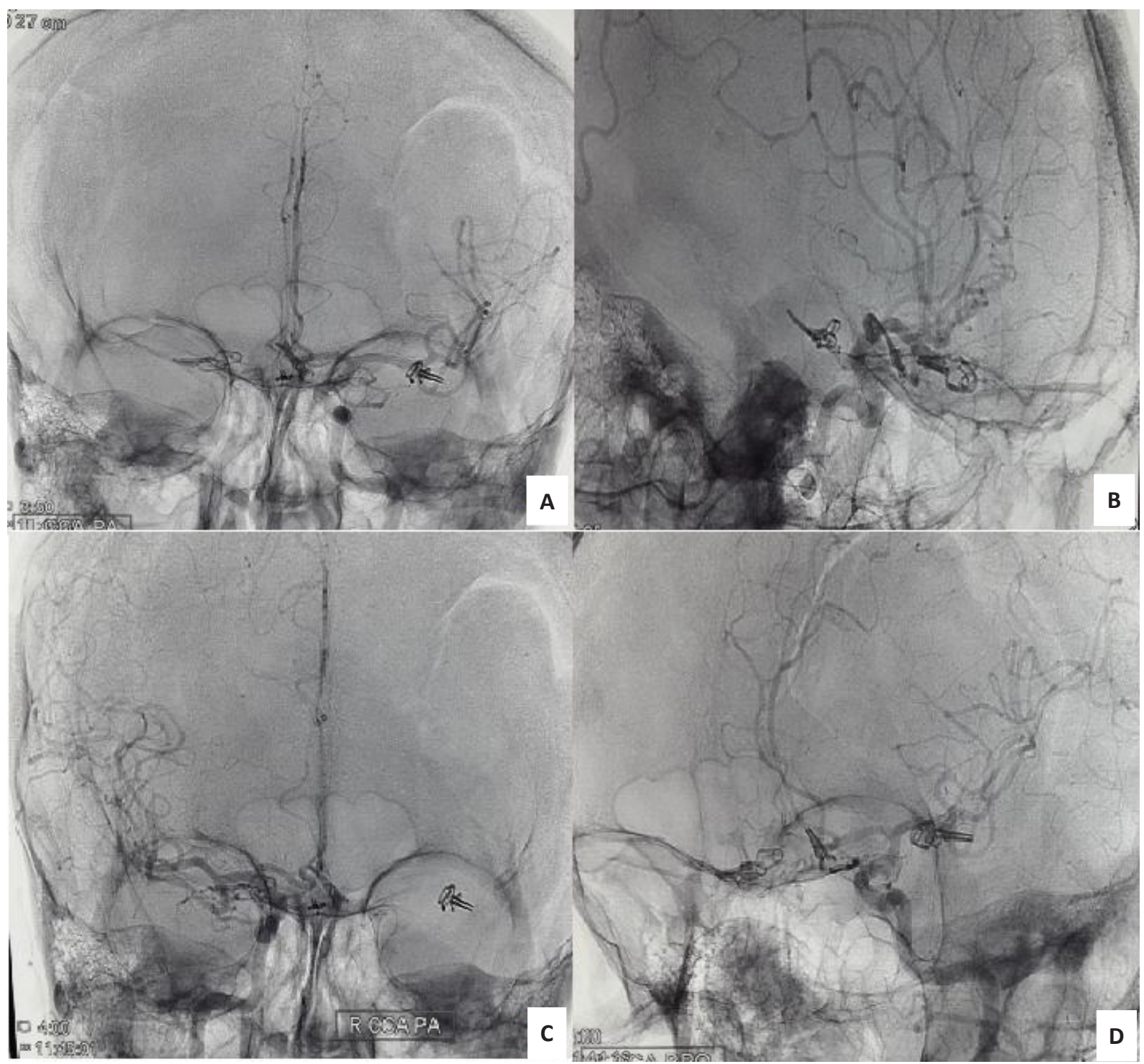

Figure 3. Early postoperative DSA demonstrates that all four aneurysms were clipped without rest; [A and C]: Anteroposterior aspect of early postoperative DSA demonstrates that all aneurysms were clipped without rest (4A: DSA image of the left Common Carotid Artery (CCA); 4C: DSA image obtained from right CCA); [B and D]: Lateral aspect of early postoperative DSA demonstrates that all aneurysms were clipped without rest (4B: DSA image of the left Common Carotid Artery (CCA); 4D: DSA image of the right CCA). 


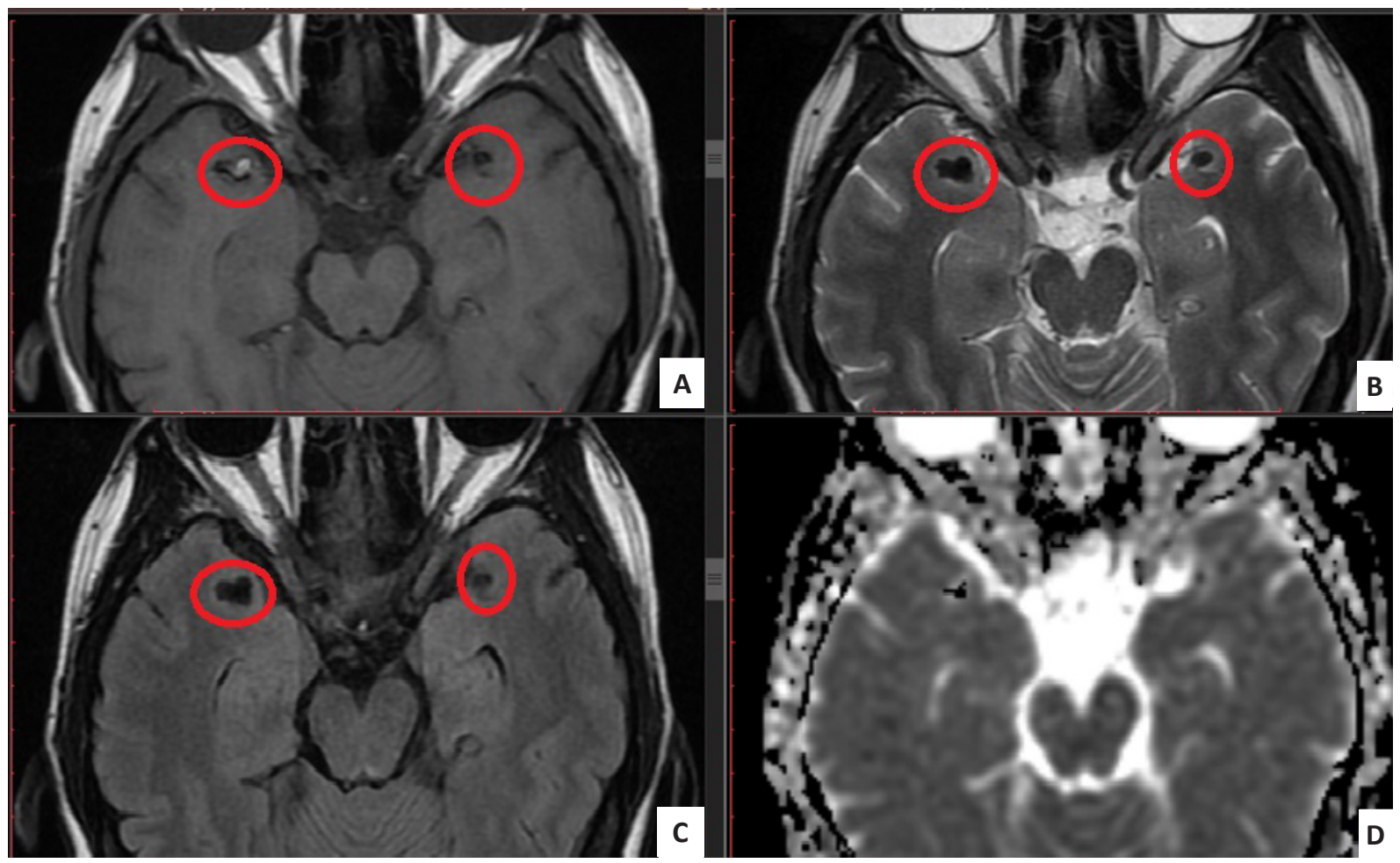

Figure 4. Preoperative magnetic resonance images (MRI) revealed bilateral middle cerebral artery aneurysms. The red cycles indicate the aneurysms; [A]: T1-weighted MRI; [B]: T2-weighted MRI; [C]: T2-flair-weighted MRI, [D]: Apparent diffusion coefficient (ADC).

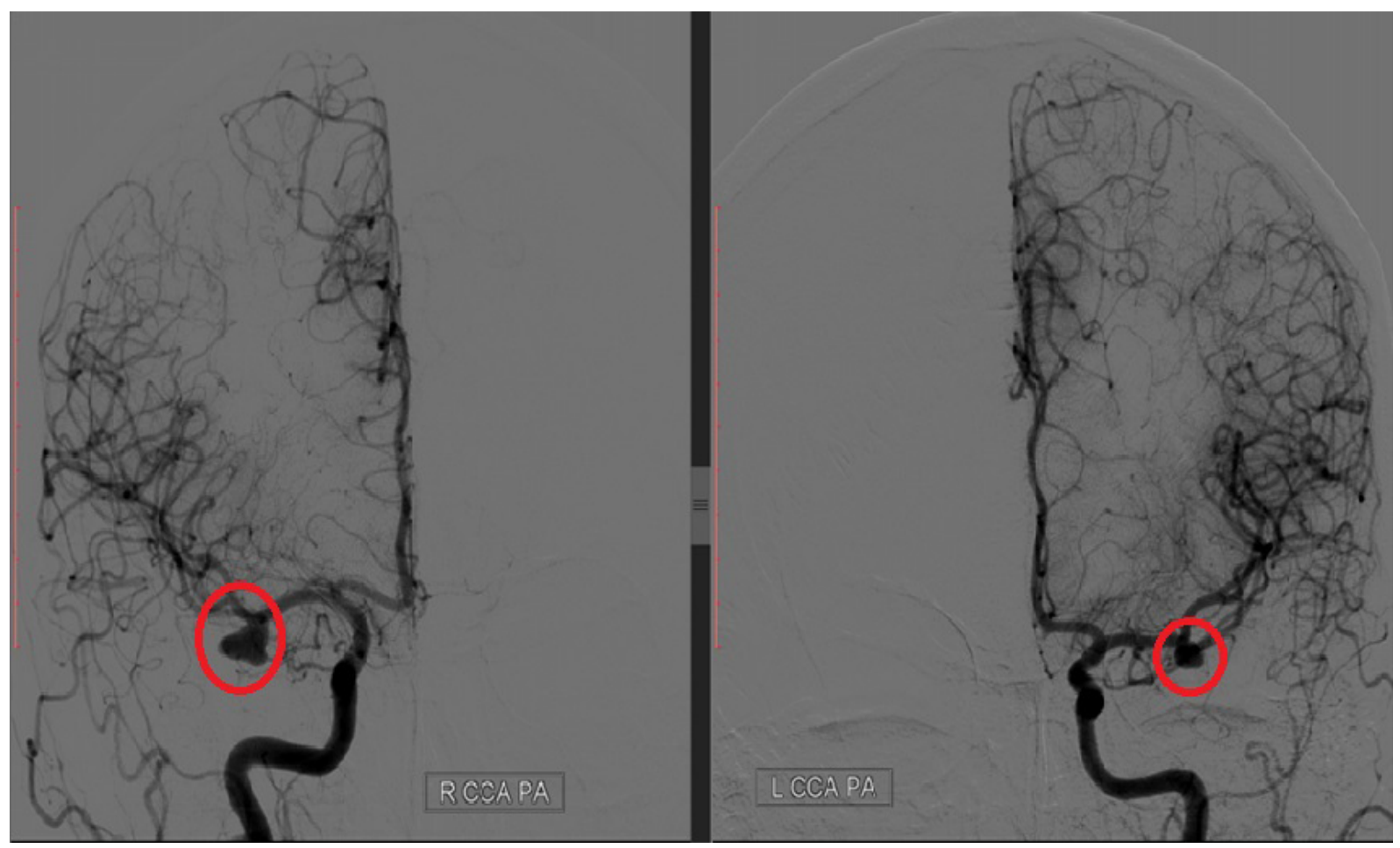

Figure 5. Preoperative DSA shows multiple aneurysms of bilateral middle cerebral artery. The red cycles indicate the aneurysms; [Right side]: Preoperative DSA shows right MCA aneurysm; [Left side]: Preoperative DSA shows left MCA aneurysm. 


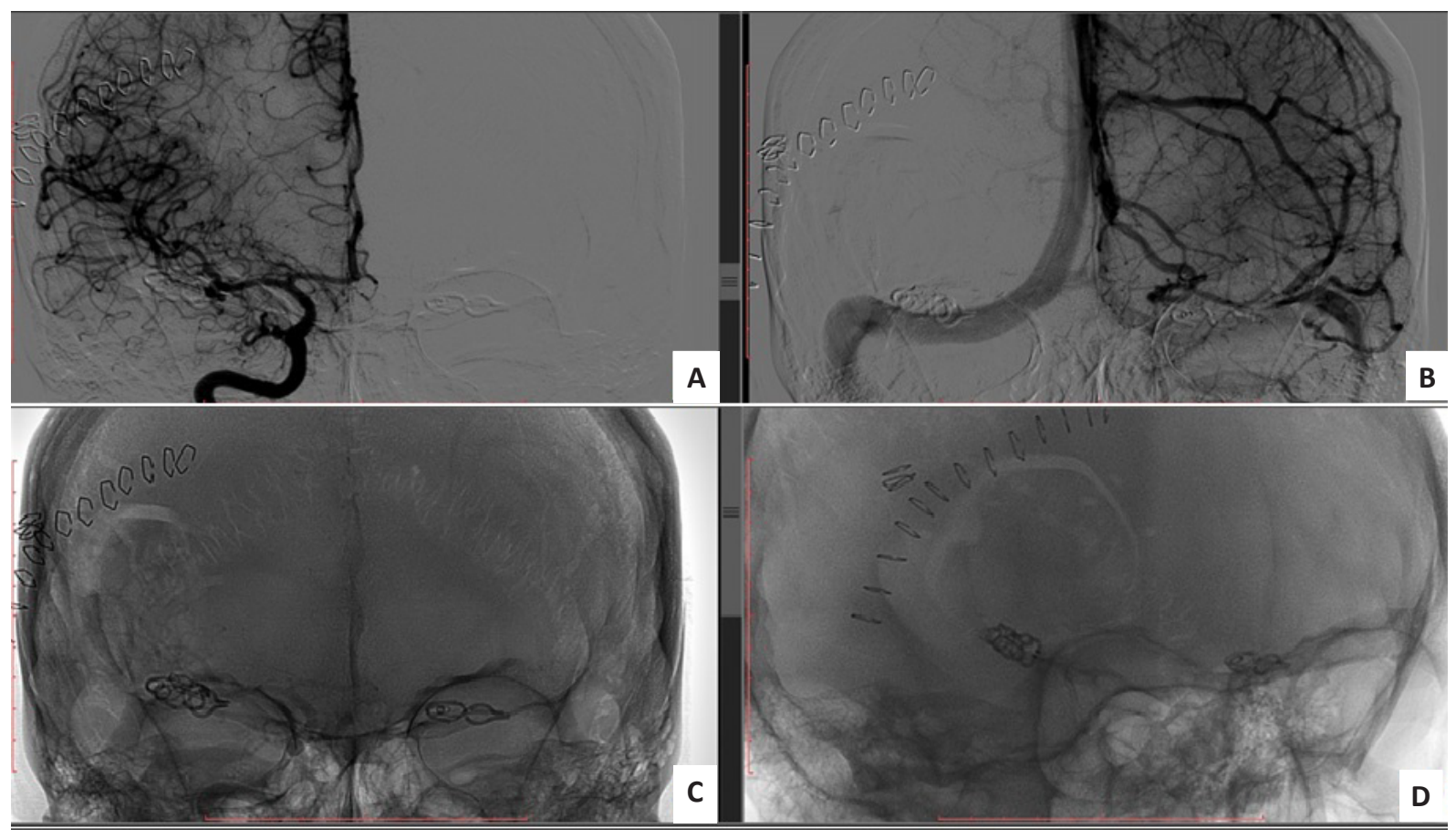

Figure 6. Early postoperative DSA demonstrates that all four aneurysms were clipped without rest; [A]: Coronal aspect: Rt. MCA aneurysm was clipped; [B]: Coronal aspect: Lt. MCA aneurysm was clipped; [C]: Anteroposterior aspect; [D]: Lateral aspect.

physician has to balance the rupture risk and treatment of the patients after discussing this with the patients with unruptured IAs and their first-degree relatives. Two systemic review studies have suggested that the predictors of higher risk of IAs getting ruptured includes several factors such as history of aneurysmal SAH, hypertension, and coronary artery disease, as well as many different demographic factors such as geographical region, age, aneurysm size (IAs with a diameter greater than $7 \mathrm{~mm}$ ) and the locations of IAs on the ACOA, PCOA, and vertebrobasilar arteries ${ }^{(13,14)}$. The IAs with these factors are more fragile and have a high propensity to rupture than other IAs.

Smoking, younger age and multiplicity of IAs at the presentation are independent risk factors for recurrent $\mathrm{SAH}{ }^{(7,15)}$. Another retrospective study found that hypertension was a serious risk factor for aneurysm regrowth or de novo aneurysm formation (15). Several studies showed that both hypertension and smoking are risk factors for the development of IAs, presenting either incidentally or with $\mathrm{SAH}$. In our series, small number of (7/274) patients presented with recurrent aneurysmal SAH which was insuffici- ent to generalize our findings, however,our findings supported the results obtained from the literature regarding recurrent SAHs that multiple IAs, smoking, and hypertension were independent risk factors for recurrent $\mathrm{SAH}(\mathrm{P}<0.01)$.

As we showed in our previously published studies (7) our findings demonstrated that presenting with poor neurological status, presence of hematoma and loss/ impairment of consciousness in aneurysmal SAH patients are independent risk factors that can be associated with poor prognosis. The location of aneurysms have an impact on the prognosis of IAs. We found that patients with MCA aneurysms had a high mortality while the patients with ACOA, ICA-PCOA and paraophthalmic segment aneurysms had a high morbidity rates $(\mathrm{GOS}<3)$. Postoperative hydrocephalus was observed in particularly SAH group with MIAs.

In their most recent study Foreman et al. found that nosocomial infection is independently associated with delayed cerebral ischemia. They suggested that this association is hypothesized to be partly causative through the exacerbation of systemic inflammation leading to thrombosis and subsequent ischemia ${ }^{(16)}$. 


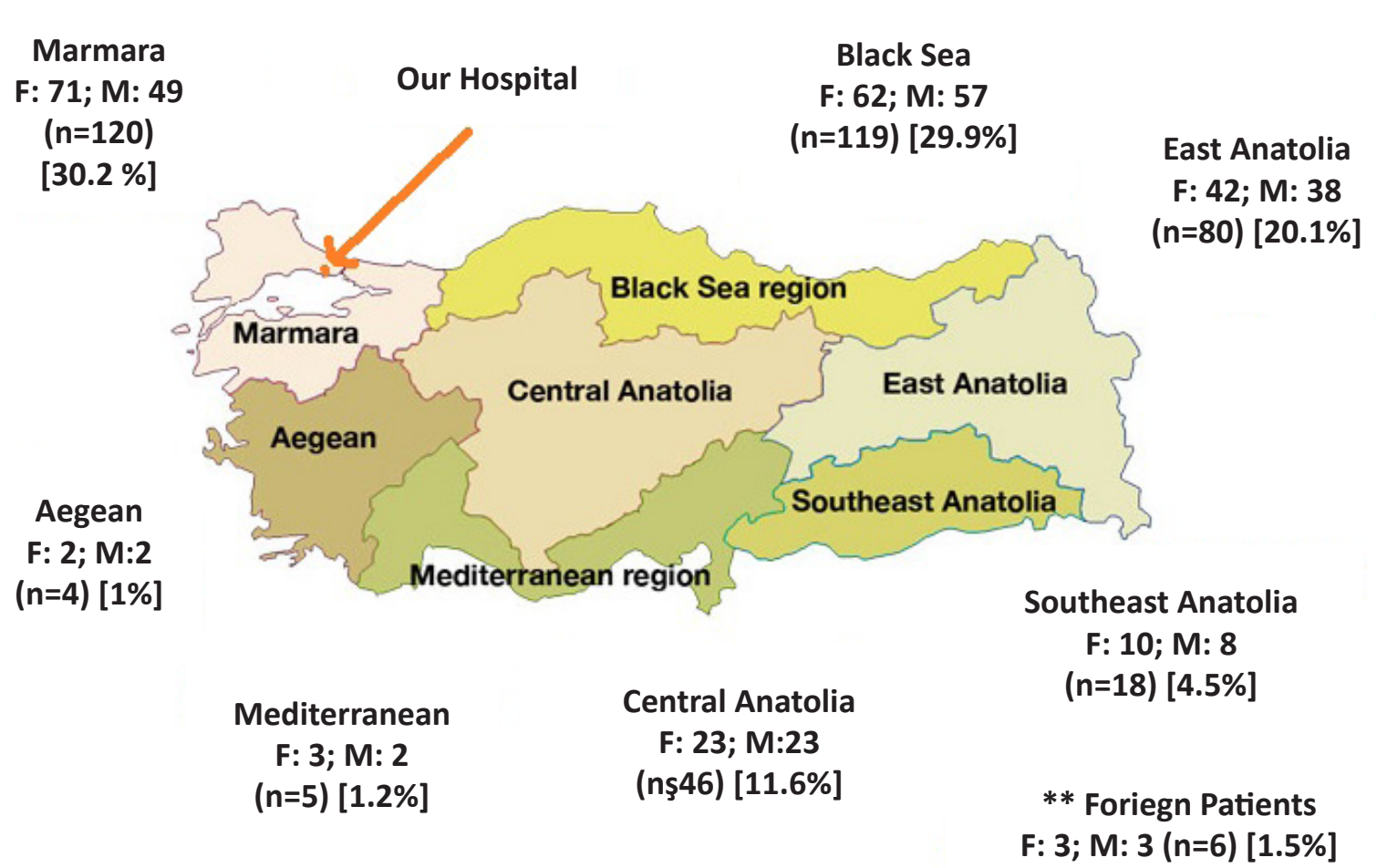

Figure 7. Demographic distribution of 398 IA patients according to geographic regions they came from.

In our series, postoperative infections observed among the patients with SAH were related to MIAs or ruptured ACoA rather than other IAs. We interpreted this by the general impairment of the immune system in the patients with SAH due to the general fatigue related to $\mathrm{SAH}$ itself, whereas the same impact of SAH was not observed in other neurosurgical disorders even though both groups underwent intracranial surgery and stayed longer in ICU. Regarding our results, infection rates increased coherent to Fisher grade rather than the Hunt-Hess scale. We thought this was associated with the increased amount of blood in the cisterns leading to adhesion of the brain. This adhesion may further suppress immunity in the brain. The morbidity rates (GOS <3) of SAH patients were higher especially of those diagnosed with MIAs. Even the exact mechanism is not clear, we found that SAH affected the immune state of the patients negatively.

The limitations of our study were as follows 1 ) the sample size was relatively small to generalize all results and findings to endemic geographic areas, 2) single healthcare institute outcomes, and 3) the retrospective design of the study. Our findings need to be confirmed /supported by further prospective randomized studies with larger samples and longer follow-up periods so as to improve the representativeness of our findings.

\section{CONCLUSIONS}

Compared to the patients diagnosed with IAs incidentally, the patients that presented with SAH had higher morbidity and mortality rates. Even though the multiplicity of IAs at presentation did not influence surgical outcomes, a higher rate of postoperative hydrocephalus was observed in SAH patients with multiple aneurysms. There was no relationship between gender of the patients, and morbidity or mortality rates. Advanced age $(>65)$ and MCA location of IA were associated with a higher mortality rate, while locations of IAs on ICA (especially para-ophthalmic), posterior, and anterior communicating arteries were associated with a higher morbidity rate.

Ethics Committee Approval: Secretary General of Istanbul Bakırköy Regional Public Hospitals Association Bakırköy Dr. Approval of Ethics Committee of Mazhar Osman Health and Neurological Diseases 
Training Hospital (30.06.2016 - 29376).

\section{Conflict of Interest: None.}

\section{Funding: None.}

Informed Consent: Informed consent was obtained from all individual participants included in the study.

\section{REFERENCES}

1. Broderick JP, Viscoli CM, Brott T, et al. Major risk factors for aneurysmal subarachnoid hemorrhage in the young are modifiable. Stroke. 2003;34:1375-81.

https://doi.org/10.1161/01.STR.0000074572.91827.F4

2. Steiner T, Juvela S, Unterberg A, Jung C, Forsting M, Rinkel G. European stroke organization guidelines for the management of intracranial aneurysms and subarachnoid haemorrhage. Cerebrovasc Dis. 2013;35:93-112. https://doi.org/10.1159/000346087

3. Rinkel GJ, Djibuti M, Algra A, van Gijn J. Prevalence and risk of rupture of intracranial aneurysms: A systematic review. Stroke. 1998;29:251-6. https://doi.org/10.1161/01.STR.29.1.251

4. Baumann F, Khan N, Yonekawa Y. Patient and aneurysm characteristics in multiple intracranial aneurysms. Acta Neurochir Suppl. 2008;103:19-28. https://doi.org/10.1007/978-3-211-76589-0_6

5. Juvela S. Risk factors for multiple intracranial aneurysms. Stroke. 2000;31:392-7. https://doi.org/10.1161/01.STR.31.2.392

6. Kaminogo M, Yonekura M, Shibata S. Incidence and outcome of multiple intracranial aneurysms in a defined population. Stroke. 2003;34:16-21. https://doi.org/10.1161/01.STR.0000046763.48330.AD

7. Asiltürk M, Abdallah A. Clinical outcomes of multiple aneurysms microsurgical clipping: Evaluation of 90 patients. Neurol Neurochir Pol. 2018;52(1):15-24. https://doi.org/10.1016/j.pjnns.2017.09.005

8. Abdallah A. Commentary: Orbitozygomatic craniotomy for clipping a complex middle cerebral artery aneurysm: 2-dimensional operative video. Oper Neurosurg (Hagerstown).
2020;18(2):E34-E35.

https://doi.org/10.1093/ons/opz324

9. Dundar TT, Abdallah A, Yurtsever I, Guler EM, Ozer OF, Uysal O. Serum SUR1 and TRPM4 in patients with subarachnoid hemorrhage. Neurosurg Rev. 2019. doi: 10.1007/s10143-01901200-6. https://doi.org/10.1007/s10143-019-01200-6

10. Dundar TT, Aralasmak A, Kitiş S, Yılmaz FT, Abdallah A. Comparison of subtracted computed tomography from computed tomography perfusion and digital subtraction angiography in residue evaluation of treated intracranial aneurysms. World Neurosurg. 2019;132:e746-e751. https://doi.org/10.1016/j.wneu.2019.08.028

11. Nieuwkamp DJ, Setz LE, Algra A, Linn FH, de Rooij NK, Rinkel GJ. Changes in case fatality of aneurysmal subarachnoid haemorrhage over time, according to age, sex, and region: A meta-analysis. Lancet Neurol. 2009;8(7):635-42. https://doi.org/10.1016/S1474-4422(09)70126-7

12. Cardis $E$, Hatch $M$. The Chernobyl accident-an epidemiological perspective. Clin Oncol (R Coll Radiol). 2011;23(4):25160. https://doi.org/10.1016/j.clon.2011.01.510

13. Backes $D$, Vergouwen MD, Velthuis BK, et al. Difference in aneurysm characteristics between ruptured and unruptured aneurysms in patients with multiple intracranial aneurysms. Stroke. 2014;45(5):1299-303. https://doi.org/10.1161/STROKEAHA.113.004421

14. Greving JP, Wermer MJ, Brown RD Jr, et al. Development of the PHASES score for prediction of risk of rupture of intracranial aneurysms: A pooled analysis of six prospective cohort studies. Lancet Neurol. 2014;13(1):59-66. https://doi.org/10.1016/S1474-4422(13)70263-1

15. Wermer MJH, vander Schaaf IC, Velthuis BK, Algra A, Buskens E, Rinkel GJE. Follow-up screening after subarachnoid haemorrhage: Frequency and determinants of new aneurysms and enlargement of exiting aneurysms. Brain. 2005;128: 2421-9. https://doi.org/10.1093/brain/awh587

16. Foreman PM, Chua M, Harrigan MR, et al. Association of nosocomial infections with delayed cerebral ischemia in aneurysmal subarachnoid hemorrhage. J Neurosurg. 2016;125(6): 1383-9.

https://doi.org/10.3171/2015.10.JNS151959 